\title{
A NEW SAFETY CULTURE MEASUREMENT TOOL AND ITS APPLICATION
}

\author{
LEI WANG \& RUISHAN SUN \\ National Key Laboratory of Air Traffic Operational Safety Technology, \\ Civil Aviation University of China, Tianjin 300300, China.
}

\begin{abstract}
Safety culture has become an important issue in research and industry field due to its latent implications on safety performance. The main aim of this research was to develop a reliable tool to measure organizational safety culture in a quantitative way. First, the dimensions and components of safety culture were analyzed and an integrated safety culture model (ISCM) was developed for describing the two-level structure of safety culture. Second, two forms of safety culture evaluation index system were constructed and every index was described in intrinsic latency and extrinsic indication level. Then the weights of index were determined using the Delphi method and the reliability of the index system was also examined based on data from survey. Third, the fuzzy comprehensive evaluation procedure on safety culture was proposed and the evaluation case was also given. The application case proved the effectiveness and reliability of this measurement tool.
\end{abstract}

Keywords: Safety culture, measurement tool, evaluation index system.

\section{INTRODUCTION}

Safety culture is a natural part of organizational culture and alludes to individual, job and organizational features that affect and influence health and safety [1]. It was proposed as a term by the International Nuclear Safety Advisory Group of the International Atomic Energy Agency (IAEA) in 1986 after their analysis on the nuclear reactor accident at Chernobyl [2].

Generally within complex sociotechnical systems, around $75 \%$ of all accidents and safety-compromising incidents are attributed to human errors [3]. However, human failure of the frontline operator, in many accidents, represents only a superficial cause. As a matter of fact, lots of accidents could be traced to organizational reasons [4-7]. The Swiss Cheese Model and organizational accident theory developed by James Reason indicated that the root reason of individual unsafe acts always could be found on organizational level, and organizational factors would affect human and local workplace factors through latent conditions pathways. Safety culture is a major part of these latent conditions and always determines the efficiency of safety management of high-risk organizations. Standing on this perspective, it was generally accepted that organizational accident is the consequence of poor safety culture. Managing safety has become increasingly more important in aviation and other high-reliability, safety critical systems [8]. Safety culture will play a more critical role in improving safety as the International Civil Aviation Organization pointed out 'An effective way to promote a safe operation is to ensure that an operator has developed a positive safety culture' [9].

Lots of theories and models regarding safety culture have been developed in such diverse domains as risk management (e.g. [10, 11]), human factors [12], aviation (e.g. [13]) and so on. Reason [14], Cooper [1], Wiegmann [12], Edwards [15] and Bentley [16] both researched the definition of safety culture and identified the dimensions and components of safety culture. Though there have been numerous fruitful products in this filed, the tool of measuring safety culture in a quantitative way was rarely detected in previous research. Obviously, safety culture measurement plays a key role in the safety improving process because it can 
evaluate the current state of a particular safety culture, as well as determine whether interventions have been effective in achieving a desired cultural change.

In the European Commission FP6 project called HILAS (Human Integration into the Lifecycle of Aviation Systems, AIP4-CT-2005-516181), one of our main tasks was to develop an applicable safety culture measurement tool for aviation organizations. Based on task requirements, we proposed an Integrated Safety Culture Model (ISCM) and developed a complete safety culture measurement tool kit including evaluation index system, questionnaire and implementation program $[17,18]$. This tool kit has been applied into several airlines for safety culture survey in China and Europe. This paper aims at introducing the whole work of developing the new safety culture measurement tool and an implementation case of its application.

\section{INTEGRATED SAFETY CULTURE MODEL}

\subsection{Definition and dimension}

In our research, safety culture was defined as follows: 'safety culture is the assembly of values, beliefs, attitudes, norms, organizational characteristic behaviors and environments which are concerned with safety, created and nourished in the long-term process of organizational producing practice, and accepted by most members in an organization'.

Safety culture was described as a two-level structure of intrinsic latency level and extrinsic indication level. Safety philosophy is attributed in latency level, and safety environment and safety behavior are attributed in indication level (see Fig. 1).

Safety philosophy represents an individual's values, beliefs, perceptions and attitudes about safety at a psychological level. Safety environment means hardware and software provided by an organization for ensuring safe operation of that organization. Safety behavior means both organizational and individual behaviors in safety practice. Meanwhile, we can see from Fig. 1 that the three parts of safety culture will affect each other, e.g. (a) all of intrinsic dimensions could be embodied in extrinsic dimensions; (b) working environment will affect people's safety behavior through affecting their psychological state like mood, sentiment and so on.

Safety philosophy and safety environment contain three dimensions each, and safety behavior contains five dimensions, it is as shown in Fig. 2 and full explanation of every dimension could be found in the work of Wang et al. [17].

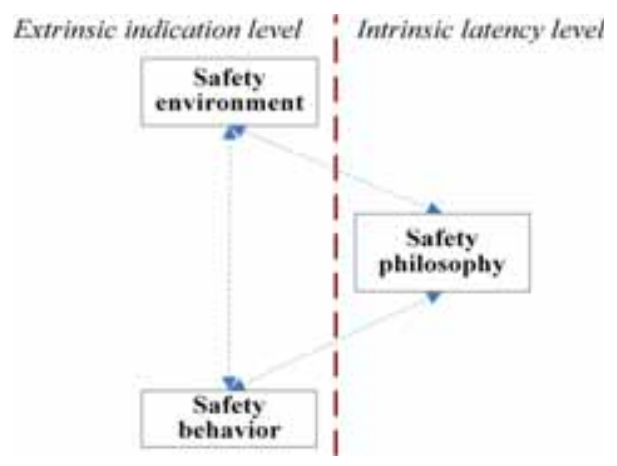

Figure 1: The two-level structure of safety culture. 


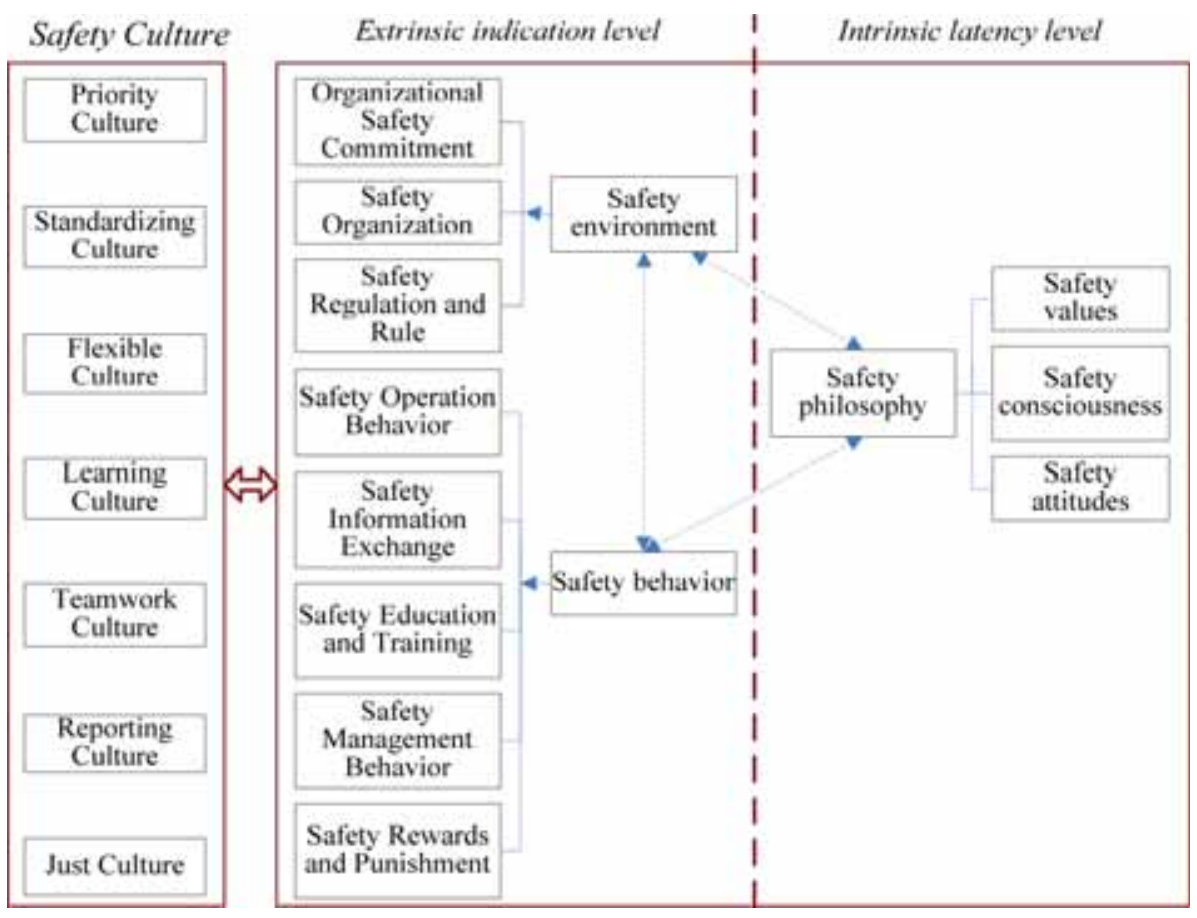

Figure 2: Integrated safety culture model.

\subsection{Integrated safety culture model}

Meanwhile, safety culture was classified as seven sub-cultures which are safety priority culture, standardizing culture, flexible culture, learning culture, teamwork culture, reporting culture and just culture. In a safety priority culture, both organizations and individuals can consider safety issues as a priority when they make every decision and behavior in their workplace. In a standardizing culture, organizational regulations, rules and standards are complete, applicable and up to date; individuals also can comply with those regulations, rules and standards completely. In a flexible culture, both organizations and individuals can discover and resolve safety matters well, when they face risk and change. In a learning culture, both organizations and individuals show positive and supportive attitudes and behaviors to all kinds of learning, including education, training and self-learning. In a teamwork culture, individuals behave with a trusting attitude and a spirit of cooperation to their co-workers. They share knowledge and skills and join in each other's activities. In a reporting culture, organizations will actively gather and analyze all kinds of safety information and individuals will present a positive attitude and behavior in relation to reporting and communicating safety information. In a just culture, both the reward and monitoring system are complete and operated fairly for everyone. Most individuals within the organization feel satisfied about this.

Then the ISCM was put forward based on the definition (Fig. 2). The model divided safety culture into intrinsic latency level, which includes all dimensions of safety philosophy, and extrinsic indication level, which includes all dimensions of safety environment and safety behavior. The eight dimensions in extrinsic indication level could be attributed to the seven 
safety sub-cultures, and then the model demonstrated the potential relationship between safety sub-culture and all safety culture dimensions [17].

\section{EVALUATION INDEX SYSTEM AND QUESTIONNAIRE}

\subsection{Structure of index system}

The evaluation index system was used to develop the safety culture questionnaire; therefore, the index system should be complete and indices should be logical enough for accurate measurement on safety culture. Based on ISCM, two forms of safety culture evaluation index system was presented, one of which was categorized from the perspective of the extrinsic indication dimensions of safety culture as Fig. 3, and another one was from the perspective of the sub-culture component as in reference [18].

Obviously, it is quite difficult to evaluate safety culture through measuring intrinsic dimensions such as an individual's philosophy/mental state. However, we have mentioned that all of the intrinsic dimensions could be embodied in extrinsic dimensions, so safety culture could be evaluated through measuring extrinsic dimensions. Two forms of index systems contain the same third layer indices, their differences just exist in position and sequence. These two forms make it possible to evaluate safety culture from the two different perspectives. Each evaluation index was described in detail in reference [18].

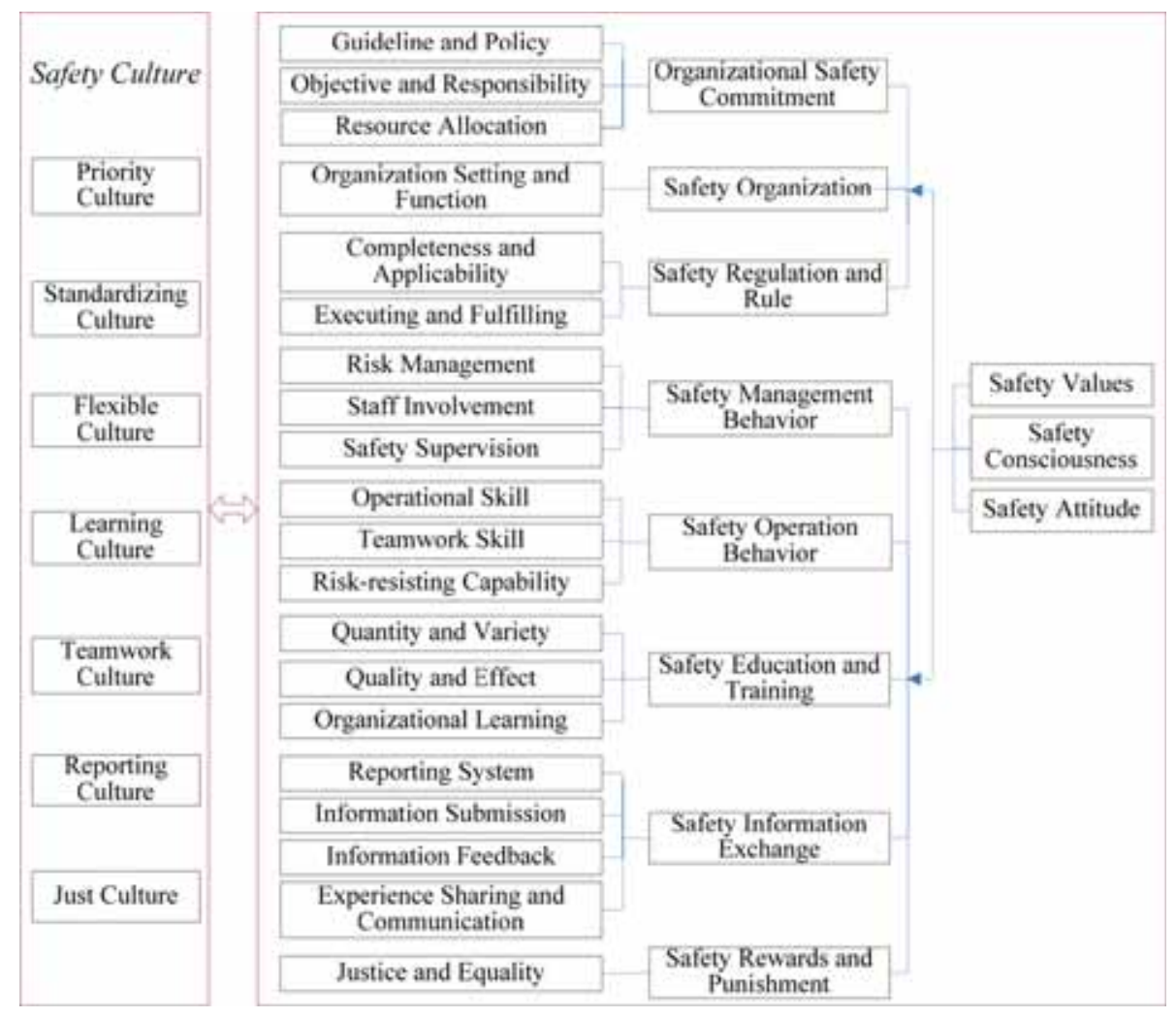

Figure 3: One form of evaluation index system. 


\subsection{Weight of index}

The Delphi method was used to calculate the weighting of the different indices. The main steps of determining index weight in this research and the calculation method of rating score was shown in previous work [18].

\subsection{Questionnaire}

A safety culture questionnaire was designed as showing in the Appendix based on the index system and there were 1 or 2 questions matched with each evaluation index.

\subsection{Reliability analysis}

One hundred and twenty-three copies of the questionnaires were distributed to a local airline in Tianjin, and the data was used to examine the reliability of the evaluation index (the consistency of a set of tests or questionnaire items). The obtained alpha coefficient, using SPSS 13.0, of the 20 items is 0.856 , which indicated that the scale has adequate reliability. The overall reliability (Cronbach's alpha) of the survey varies from at the lowest 0.833 to the highest 0.856 if one of the items is deleted. None of the values is greater than the current alpha of the whole scale (0.856), so it is not necessary to delete any of the items to improve the reliability score of this scale.

\section{THE EVALUATION METHOD}

The method of multifactor hierarchical fuzzy comprehensive evaluation is used to evaluate these factors attributing to safety culture. The evaluation index system has two levels; consequently, the comprehensive evaluation method will be preceded twice. First, the evaluation results of the first layer indices are figured out according to fuzzy comprehensive evaluation of the second layer indices, and then the evaluation results of the whole safety culture could be obtained after the fuzzy comprehensive evaluation of the first layer indices. The detailed steps are as follows:

(1) Factors set and the alternative set

The index sets in the first layer:

$$
\begin{aligned}
& U=\left\{u_{1}, u_{2}, \ldots, u_{n}\right\}=\left\{u_{1}, u_{2}, u_{3}, u_{4}, u_{5}, u_{6}, u_{7}\right\}=\{\text { Priority Culture, } \\
& \text { Standardizing Culture, Flexible Culture, Learning Culture, } \\
& \text { Teamwork Culture, Reporting Culture and Just Culture }\}
\end{aligned}
$$

The index sets in the second layer is just similar to the first layer.

The alternative set:

$$
V=\left\{v_{1}, v_{2}, \ldots, v_{\mathrm{m}}\right\}=\left\{v_{1}, v_{2}, v_{3}, v_{4}, v_{5}\right\}=\{1,2,3,4,5\}
$$

(2) Weights assignment

The weight set of the first layer index:

$$
A=\left\{a_{1}, a_{2}, a_{3}, a_{4}, a_{5}, a_{6}, a_{7}\right\}
$$

The weight set of the second layer index:

$$
A_{i}=\left\{a_{i 1}, a_{i 2}, \ldots, a_{i n}\right\}, i=1,2, \ldots, 7
$$


(3) Fuzzy relationship matrix

Fuzzy comprehensive judgment matrix $R$ reflects the relationship between index and evaluation grade, namely the fuzzy relationship from $U$ to $V$. The judgment matrix of the second layer index can be got from statistical results of the questionnaire. First, the membership degree $u_{i j}^{m}$ and single factor judgment value $r_{i j}$ should be calculated by formulas as follows:

$$
\begin{gathered}
u_{i j}^{m}=n_{i j m} / n \\
r_{i j}=u_{i j}^{1} / V_{1}+u_{i j}^{2} / V_{2}+\ldots \ldots .+u_{i j}^{5} / V_{5}
\end{gathered}
$$

$n$ indicates the number of questionnaires returned; $V_{m}(m=1,2,3,4,5)$ indicates the evaluation grade; $n_{i j m}$ indicates the appearance frequency of the evaluation grade $V_{m}(m=1,2,3,4,5)$.

Then we can get judgment matrix of the second layer indices as following.

$$
\begin{aligned}
& R_{i}=r_{n \times 5}=\left(\begin{array}{ccccc}
r_{11}{ }^{i} & r_{12}{ }^{i} & r_{13}{ }^{i} & r_{14}{ }^{i} & r_{15}{ }^{i} \\
r_{21}{ }^{i} & r_{22}{ }^{i} & r_{23}{ }^{i} & r_{24}{ }^{i} & r_{25}{ }^{i} \\
\ldots & \ldots & \ldots & \ldots & \ldots \\
r_{n 1}{ }^{i} & r_{n 2}{ }^{i} & r_{n 3}{ }^{i} & r_{n 4}{ }^{i} & r_{n 5}{ }^{i}
\end{array}\right) \\
& i=1,2, \ldots .7
\end{aligned}
$$

$n$ indicates the number of second layer indices.

(4) Compound operation on index layer

Make compound operation on the second layer index:

$$
\begin{aligned}
B_{i} & =A_{i} \times R_{i}=\left(a_{i 1}, a_{i 2}, \ldots, a_{i n}\right)\left(\begin{array}{ccccc}
r_{11}{ }^{i} & r_{12}{ }^{i} & r_{13}{ }^{i} & r_{14}{ }^{i} & r_{15}{ }^{i} \\
r_{21}{ }^{i} & r_{22}{ }^{i} & r_{23}{ }^{i} & r_{24}{ }^{i} & r_{25}{ }^{i} \\
\ldots & \ldots & \ldots & \ldots & \ldots \\
r_{n 1}{ }^{i} & r_{n 2}{ }^{i} & r_{n 3}{ }^{i} & r_{n 4}{ }^{i} & r_{n 5}{ }^{i}
\end{array}\right) \\
& =\left(b_{i 1}, b_{i 2}, b_{i 3}, b_{i 4}, b_{i 5}\right)
\end{aligned}
$$

$B_{i}$ indicates the evaluation result of Index $u_{i}$.

The fuzzy comprehensive judgment matrix for the first layer index could be expressed as:

$$
R=r_{7 \times 5}=\left(\begin{array}{ccccc}
b_{11} & b_{12} & b_{12} & b_{14} & b_{15} \\
b_{21} & b_{22} & b_{23} & b_{24} & b_{25} \\
\ldots & \ldots & \ldots & \ldots & \ldots \\
b_{71} & b_{71} & b_{73} & b_{74} & b_{75}
\end{array}\right)=\left(\begin{array}{ccccc}
r_{11} & r_{12} & r_{12} & r_{14} & r_{15} \\
r_{21} & r_{22} & r_{23} & r_{24} & r_{25} \\
\ldots & \ldots & \ldots & \ldots & \ldots \\
r_{71} & r_{71} & r_{73} & r_{74} & r_{75}
\end{array}\right)
$$

On making compound operation on the first layer index:

$$
\begin{aligned}
B & =A \times R=\left(a_{1}, a_{2}, a_{3}, a_{4}, a_{5}, a_{6}, a_{7}\right)\left(\begin{array}{ccccc}
r_{11} & r_{12} & r_{12} & r_{14} & r_{15} \\
r_{21} & r_{22} & r_{23} & r_{24} & r_{25} \\
\ldots & \ldots & \ldots & \ldots & \ldots \\
r_{71} & r_{71} & r_{73} & r_{74} & r_{75}
\end{array}\right) \\
& =\left(b_{1}, b_{2}, b_{3}, b_{4}, b_{5}\right)
\end{aligned}
$$


If the evaluation grades were matched with the corresponding score $\mathrm{C}=(20,50,70,85,95)^{T}$, the score of safety culture evaluation can be calculated by $S=B \cdot C$, and we can also get the score of each sub-culture by $S_{i}=B_{i} \cdot C_{i}$.

\section{A MEASUREMENT APPLICATION}

For verifying the effectiveness of the safety culture measurement tool proposed in this paper, a safety culture survey was conducted in one European airline, which was the HILAS partner. The safety culture survey was administered in the maintenance division of the surveyed airline. Forty-four copies of the questionnaire were distributed to the operational staff and management in June, 2009. All questionnaires were in usable condition and included in the analysis. Most respondents were male (91\%). Most (68.2\%) had been employed by the airline for less than 5 years, with $22.7 \%$ indicating that they had held their present position for $5-10$ years. Of the respondents, $59.1 \%$ had 12 or 13 years of formal school education and $20.5 \%$ had 15 years of formal school education.

The final total score of safety culture in this organization is 69.29. It ranks as 'Average' according to Table 1. The final score and rank of this survey shows that the current status of safety culture is at an average level. It means the safety culture is positive, but there still is a large scope for improvement. Meanwhile, for further and better understanding, we made a histogram to illustrate the score differences between all safety sub-cultures (see Fig. 4).

The total average score is derived from averaging the individual component scores. As shown in Fig. 4, there are no significant differences on the seven sub-cultures. But the score of the Standardising Culture (74.30) and Teamwork Culture (75.15) is higher than others. Obviously, it means these two sub-cultures are better than the other ones. First, most of the organizational regulations, rules and standards are complete, applicable and up to date; most

Table 1: Conversion rank of evaluation score.

\begin{tabular}{llllll}
\hline Score & $100-90$ & $89-80$ & $79-60$ & $59-40$ & $39-0$ \\
Rank & Excellent & Good & Average & Poor & Very poor \\
\hline
\end{tabular}

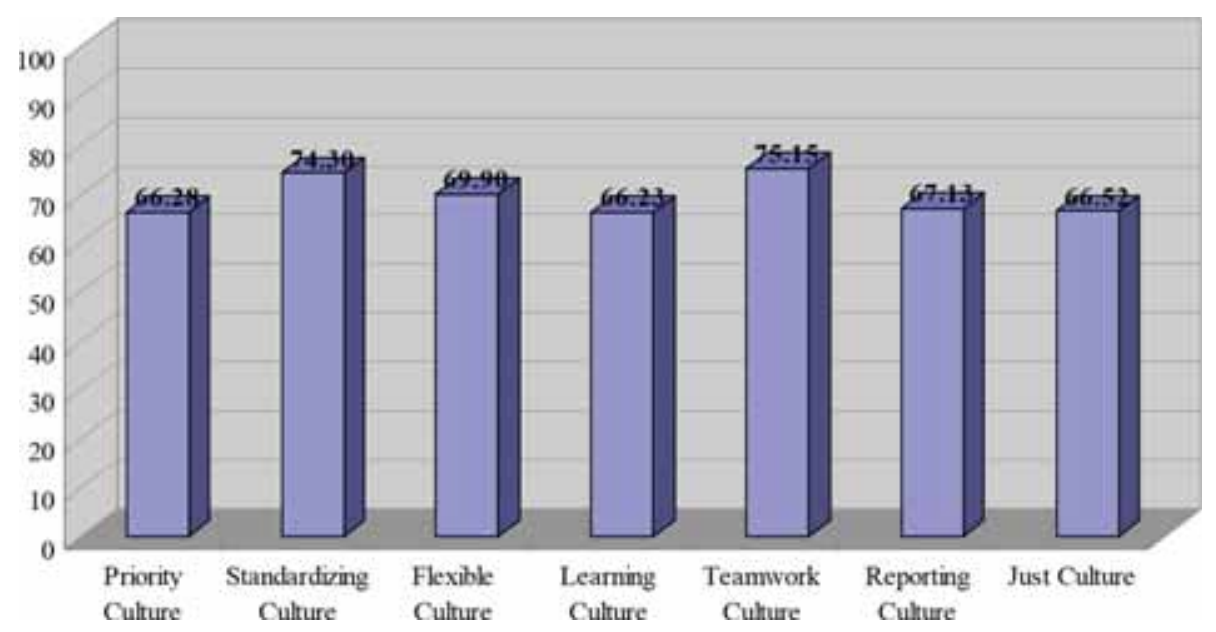

Figure 4: Score distribution of safety sub-culture. 
of staff also can comply well with those regulations, rules and standards. Secondly, most of the staff behave with a trusting attitude and cooperative skill (see above) to co-workers, and they share knowledge and join in each other's activities.

\section{CONCLUSIONS}

This paper examined the method and process of developing a new safety culture measurement tool based on Integrated Safety Culture Model. This model divided safety culture into intrinsic and extrinsic levels. All dimensions of safety philosophy were contained in intrinsic latency level and all dimensions of safety environment and safety behavior were contained in extrinsic indication level. The potential relationship between the safety sub-culture and all of the safety culture dimensions was illustrated in this model. Meanwhile, it provided the possibility of evaluating safety culture from these two perspectives. Following this, two forms of safety culture evaluation index systems were constructed and every index was described. Then the weights of the index were determined using the Delphi method and the reliability of the index system was also examined based on data from survey. Meanwhile, the questionnaire was designed and a fuzzy comprehensive evaluation solution on safety culture was proposed. The final safety culture measurement tool was also worked out and has been implemented in several aviation organizations in China and Europe. The results indicated that this safety culture quantitative measurement tool is effective and applicable and expected to be used in more diverse fields.

\section{ACKNOWLEDGEMENTS}

We appreciate the support provided by the European Commission FP6 project of HILAS (Human Integration into the Lifecycle of Aviation Systems, AIP4-CT-2005-516181) and National Basic Research Program of China (No.2010CB734105). We also appreciate the great help of Dr Marie Ward at the Trinity College, Dublin, and Mr George N. Tilton at Airworthiness Standards Institute of United States for revising the manuscript.

\section{REFERENCES}

[1] Cooper, M.D., Toward a model of safety culture. Safety Science, 36(2), pp. 111-136, 2000. doi: http://dx.doi.org/10.1016/S0925-7535(00)00035-7

[2] International Nuclear Safety Advisory Group, Developing safety culture in nuclear activities: practical suggestions to assist progress. Safety Reports Series No. 11, Vienna, Austria, 1998.

[3] Stanton, N.A. \& Salmon, P., Predicting pilot error: testing a new methodology and a multi-methods and analysts approach. Applied Ergonomics, 40(3), pp. 464-471, 2009. doi: http://dx.doi.org/10.1016/j.apergo.2008.10.005

[4] Reason, J., Human Error, Cambridge University Press: Cambridge, UK, pp. 1-3, 1990.

[5] Helmreich, R.L. \& Merritt, A.C., Culture at Work in Aviation and Medicine, Ashgate: Brookfield, VT, pp. 107-174, 1998.

[6] Wiegmann, D.A. \& Shappell, S.A., A Human Error Approach to Aviation Accident Analysis: The Human Factors Analysis and Classification System. Ashgate: Burlington, UK, pp. 10-17, 2003.

[7] Von Thaden, T.L., Hoppes, M., Johnson, N., Li, Y. \& Schriver, A., The perception of just culture across disciplines in healthcare. The Proceedings of the 50th Annual Human Factors and Ergonomics Society Conference, San Francisco, CA, p. 352, 2006.

[8] Pasman, H.J., Developments in safety science and technology. Proceedings of the 2008 International Symposium on Safety Science and Technology, Beijing, China, pp. 3-12, 2008. 
[9] International Civil Aviation Organization, Safety management manual (SMM), Document No. 9859, Montreal, 2006.

[10] Cox, S. \& Cheyne, A., Assessing safety culture in offshore environments. Safety Science, 34(1), pp. 111-129, 2000. doi: http://dx.doi.org/10.1016/S0925-7535(00)00009-6

[11] Smith, G.S., Huang, Y.-H., Ho, M. \& Chen, P.Y., The relationship between safety climate and injury rates across industries: the need to adjust for injury hazards. Accident Analysis \& Prevention, 38(3), pp. 556-562, 2006. doi: http://dx.doi.org/10.1016/j. aap.2005.11.013

[12] Wiegmann, D., Zhang, H., von Thaden, T., Gibbons, A. \& Sharma, G., Safety culture: an integrative review. International Journal of Aviation Psychology, 14(2), pp. 117-134, 2004. doi: http://dx.doi.org/10.1207/s15327108ijap1402 1

[13] McDonald, R.P., Test Theory: A Unified Treatment, Lawrence Erlbaum: Mahwah, NJ, 1999.

[14] Reason, J., Managing the Risks of Organizational Accidents. Ashgate: Hants, UK, pp. 11-14, 1997.

[15] Edwards, J.R.D., Davey, J. \& Armstrong, K., Returning to the roots of culture: a review and re-conceptualisation of safety culture. Safety Science, 55(6), pp. 70-80, 2013. doi: http://dx.doi.org/10.1016/j.ssci.2013.01.004

[16] Bentley, T. \& Tappin, D., Incorporating organisational safety culture within ergonomics practice. Ergonomics, 53(10), pp. 1167-1174, 2010. doi: http://dx.doi.org/10.1080/00 $\underline{140139.2010 .512981}$

[17] Wang, Lei, Sun, Ruishan, Liu, Hanhui \& Zou, Mei, Integrated safety culture model and its application. Journal of Civil Aviation University of China, 27(4), pp. 22-25, 2009.

[18] Wang, Lei \& Sun, Ruishan, The development of a new safety culture evaluation index system. Procedia Engineering, 43, pp. 331-337, 2012. doi: http://dx.doi.org/10.1016/j. proeng.2012.08.057

\section{APPENDIX: SAFETY CULTURE QUESTIONNAIRE}

How well do you think each of the following statements applies to your organization according to the five point scale of 'strongly disagree, disagree, unsure, agree, strongly agree'.

No. Questions

1 Safety is given a definite priority when it conflicts with the company's other interests e.g. economic.

2 Each work phase has corresponding safety goals. To ensure the safety goals are achieved the responsibilities of each phase are clear.

3 Each work phase/location is equipped with sufficient equipment, labour and financial resources.

4 I am satisfied with working conditions and the equipment/tools used in my work.

5 The safety management committees/departments/managers perform their duties and play an active role in preventing and disposing accidents.

6 The safety rules/regulations are imperfect and inapplicable, so there are few effective rules for us to follow during the work. 
No.

Questions

7 The safety rules/regulations cannot be updated in a timely manner, so there are few effective rules for us to follow during the work.

8 I do not know the safety rules that should be followed during the work.

9 Even if I know those safety rules, I don't always comply with them fully.

10 Safety inspection and risk assessment are carried out regularly in my company.

11 The defects or hazards found in safety inspection and risk assessment will be rectified promptly.

12 I am given sufficient opportunities to make suggestions and participate in the safety decision making and implementing process.

13 Violation events happen frequently in my company.

14 There is an active learning atmosphere within my company.

15 I am used to improving my skills through learning actively.

16 Team spirit and cooperation are well promoted in my company.

17 I am happy to offer help when my colleagues need support or assistance at work.

18 When other people make mistakes at work, I don't always point them out immediately, as I think it's none of my business or I'm afraid of making that person feel embarrassed.

19 I can discover the latent defects/risks during my work.

20 I can take effective timely prevention measures after discovering latent defects/risks.

21 Safety education and training are carried out frequently in my company.

22 As a result of safety education and training, the ability of staff to recognize and deal with risks has been improved significantly.

23 Self-learning and knowledge-sharing among staff are encouraged in my company.

24 There are various ways to facilitate knowledge-sharing in my company, such as establishing network based platforms for communication, holding seminars and distributing brochures.

25 Safety information reporting, including mandatory and confidential safety reporting, is carried out in my company.

26 The company safety information reporting system is operated well and used widely.

27 I often contribute and obtain all kinds of safety information through the company safety information reporting system.

28 I cannot always receive feedback in a timely manner after I make safety suggestions to safety management leaders.

29 I can often learn from incidents/accidents that have happened.

30 I can often improve my experience and knowledge through communicating with my colleagues.

31 The rewards and punishment measures of the company are fair, just and open.

32 I am satisfied with my company's rewards and punishment measures. 